\title{
Interaction of antithrombin III with preadsorbed albumin-heparin conjugates
}

\author{
W.E. Hennink, C.D. Ebert*, S.W. Kim*, W. Breemhaar, A. Bantjes and J. Feijen \\ Department of Chemical Technology, Biomaterials Section, Twente University of Technology, Enschede, The Netherlands \\ *Department of Pharmaceutics, University of Utah, Salt Lake City, USA, 84112 \\ (Received 9 October 1983; accepted 20 December 1983)
}

\begin{abstract}
The adsorption of antithrombin III (AT III) onto polystyrene surfaces preadsorbed with albumin or albuminheparin conjugates was studied using a two step enzyme immuno assay. When AT III-buffer solutions were used, the highest adsorption values were measured on high affinity albumin-heparin conjugate pretreated surfaces. Less AT III adsorption was found on nonfractionated albumin-heparin conjugate preadsorbed surfaces. AT III adsorption could also be detected on low affinity conjugate and albumin coated surfaces. When AT III was adsorhed from plasma or plasma dilutions with buffer, only AT III on surfaces preadsohed with high affinity or nonfractionated albumin-heparin conjugate was found. These results demonstrate that the heparin moiety of the conjugate is directed to the solution phase whereas the alhumin moiety contacts the polystyrene surface
\end{abstract}

Keywords: Polymers, heparin, albumin-heparin conjugates, antithrombin III, protein adsorption

The mechanism by which heparin acls as an anticoayulant has been the subject of many papers. It is now generally accepted that heparin requires the participation of the natural coagulation inhibitor antithrombin III (AT III) to express its activity. As shown by spectroscopic techniques ${ }^{1-3}$, heparin binds strongly to AT III and induces a conformational change of this protein. The heparinAT III complex rapidly neutralizes the activity of activated clotting factors (thrombin, factors XIla, Xla, Xa, IXa) yielding an inactive heparin-AT III-clotting factor complex. Subsequently, heparin is released from this ternary complex and is then available for further reactions. A review concerning the mechanism of the anticoagulant action of heparin was recently published by Björk and Lindahl ${ }^{4}$. The binding of AT 111 to heparin is not only important for the anticoagulant activity, but also plays a role in heparin-platelet interactions as was observed for heparin in solution ${ }^{5,6}$ as well as for immobilized heparin ${ }^{7}$. Although the mechanism of the anticoagulant action of heparin in solution is well known, the reasons for the observed enhanced antithrombogenicity of materials after heparinization are still not fully understood. Both the release of heparin from the surface into the blood phase as well as the action of surface bound heparin have been mentioned as causes for the observed enhanced antithrombogenicity ${ }^{8-10}$. Although the role of AT III binding onto heparin in solution has been extensively investigated, the adsorption of AT III onto heparinized materials has received less attention ${ }^{11,12}$
Recently we reported on the use of alburnir-heparin conjugates for the improvement of the blood compatibility of polymeric surfaces either by preadsorption or by covalent coupling of the conjugates ${ }^{13}$. The in vitro blood compatibility of materials preadsorbed with albuminheparin conjugates was strongly improved. Compared with control materials, platelet adhesion onto materials preadsorbed with albumin-heparin was reduced ${ }^{14}$ and it was shown that these surfaces also inhibited the surface induced coagulation ${ }^{15,16}$

As pointed out above, binding of AT III onto heparinized materials is possibly important for both the neutralization of formed activated clotting factors at the blood-polymer interface and for reduction of immobilized heparin-platelet interactions. In this paper we describe the results of the adsorption of AT III from plasma and from buffer containing purified AT III onto polystyrene preadsorbed with different albumin-heparin conjugates and albumin. A two step enzyme immuno assay (E|A) as described by Breemhaar et al. ${ }^{17,18}$ was used to detect adsorbed AT III.

\section{MATERIALS AND METHODS}

\section{Materials}

All experiments described here were carried out using multiwell polystyrene microtitre plates (110 wells) obtained from Organon Technika, Turnhout, Belgium. 


\section{Reagents}

Human serum albumin (A 9511) was obtained from Sigma, St Louis, USA. Heparin $(170 \mathrm{U} / \mathrm{mg})$ from porcine mucosa was obtained from Diosynth, Oss, The Netherlands. 1-Ethyl-3-(3-dimethylaminopropyl)-carbodiimide (EDC) was a product of Aldrich, Beerse, Belgium. Purified human antithrombin III (AT III) was a generous gift of the American Red Cross. Human CPD plasma was obtained from the bloodbank Twente and Achterhoek, Enschede, The Netherlands. Rabbit sera directed against human albumin, human AI III and sheep serum directed against rabbit immunoglobulin (ShalgG) were obtained from the Central Laboratory of the Netherlands Red Cross Blood Transfusion Service, Amsterdam, The Netherlands. Horse radish peroxidase was purchased from Boehringer, Mannheim, FRG. Urea peroxide was a product of Organon Technika, Turnhout, Belgium. 3, 3', 5, 5'-Tetramethylbenzidine was purchased from Fluka, Switzerland. $\mathrm{N}$-succinimidyl-3-(2-pyridyldithio)propionate (SPDP) was obtained from Pharmacia Fine Chemicals, Uppsala, Sweden.

\section{Synthesis of the enzyme-anti-immunoglobulin conjugate}

Sheep anti-rabbit immunoglobulin $G$ was covalently coupled to horse radish peroxidase using SPDP as a coupling agent The procedure was described in detail by Carlsson et al. ${ }^{19}$.

\begin{abstract}
Albumin-heparin conjugates
Albumin and heparin were coupled using a water soluble carbodiimide (EDC). Unreacted albumin and heparin were separated from albumin-heparin conjugates using DEAE cellulose and Cibacron Blue Sepharose chromatography respectively, as described in detail previously ${ }^{13}$. High and low AT III affinity albumin-heparin conjugates were obtained by fractionation using immobilized AT $1 \mathrm{II}^{13}$. The albumin-heparin conjugates obtained were characterized with respect to the weight percentage of heparin in the conjugates using a metachromic assay ${ }^{13,20}$ and the anticoagulant activity using an APTT (activated partial thromboplastin time) assay ${ }^{13}$.
\end{abstract}

\section{Adsorption of albumin, albumin-heparin conjugate and AT III onto polystyrene}

Solutions of albumin, albumin-heparin conjugate and AT III were made in PBS (phosphate buffered saline, $0.9 \%$ $\mathrm{NaCl}, 10 \mathrm{mM} \mathrm{Na}_{2} \mathrm{HPO}_{4}$ adjusted with $\mathrm{HCl}$ to $\mathrm{pH} \mathrm{7.4).} \mathrm{AT} \mathrm{III}$ concentrations were determined spectrophotometrically at $280 \mathrm{~nm}$ using an extinction coefficient $E_{280}^{1 \%} \mathrm{~nm}=6.10^{21}$.

The wells of polystyrene microtitre plates were contacted for $1 \mathrm{~h}$ at $20^{\circ} \mathrm{C}$ with $75 \mu \mathrm{l}$ of serial dilutions of albumin (concentrations varied from $10^{-5}-10 \mathrm{mg} / \mathrm{ml}$ ), albumin-heparin conjugate (concentrations varied from $10^{-5}-10 \mathrm{mg} / \mathrm{ml}$ ) or AT III (concentrations varied from $10^{-5}-2 \times 10^{-1} \mathrm{mg} / \mathrm{ml}$ ) solutions in PBS.

After the addition of the protein solutions, the plates were covered in order to prevent evaporation. The protein solutions were then discarded and each well was sequentially washed 4 times with $150 \mu$ aliquots of PBS. After washing, $50 \mu \mathrm{l}$ of a solution of anti-albumin (first antibody) was added to the wells which were previously exposed to the albumin and albumin-heparin conjugate solutions and $50 \mu$ l of a solution of anti-AT III was added to the wells which were previously exposed to the different AT III solutions. The solutions of anti-albumin and anti-AT III were prepared by dilution of rabbit serum directed against human albumin and human AT III respectively a 100 times in PBS-BSA [PBS containing 1\% $(\mathrm{w} / \mathrm{v})$ of bovine serum albumin]. The adsorbed proteins were incubated with the corresponding antibody solution for $1 \mathrm{~h}$. Subsequently the antibody solution was discarded and each well was sequentially washed 4 times with $150 \mu \mathrm{l}$ aliquots of PBS. Then $50 \mu \mathrm{l}$ of an appropriate dilution of enzyme coupled anti-immunoglobulin (second antibody) in $0.02 \mathrm{M} \mathrm{Tris} / \mathrm{HCl}$ buffer containing $1 \%(\mathrm{w} / \mathrm{v})$ polyethylene glycol 6000 (obtained from Fluka. Switzerland) was added to each of the wells. After an incubation time of $1 \mathrm{~h}$, the solution of the second antibody was discarded and each well was washed 4 times with $150 \mu \mathrm{l}$ of PBS after which $100 \mu \mathrm{l}$ of substrate solution was added to each well. The substrate solution was prepared by diluting a 3, 3',5, 5'-tetramethylbenzidine $(10 \mathrm{mg} / \mathrm{ml} \mathrm{DMSO})$ solution 100 times in buffer $(0.6 \mathrm{M}$ $\mathrm{Na}$ acetate, $\mathrm{pH} 6.0$ ) which contained $1 \mathrm{ml}$ of a stock ureum peroxide solution ( 1 tablet per $10 \mathrm{ml} \mathrm{H}_{2} \mathrm{O}$ ) per $100 \mathrm{ml}$. The polystyrene plate was placed in the dark for $30 \mathrm{~min}$. followed by the addition of $2 \mathrm{M} \mathrm{H}_{2} \mathrm{SO}_{4}$ to stop the enzymatic reaction. Finally the intensity of the yellow colour formed was measured at $450 \mathrm{~nm}$ using a colorimeter(Vitatron) equipped with a $80 \mu \mathrm{l}$ flow through cell.

\section{Adsorption of AT III onto polystyrene preadsorbed with albumin or albumin-heparin conjugate}

To evaluate AT III interactions with adsorbed albumin or albumin-heparin conjugates, $75 \mu \mathrm{l}$ of a solution of albumin or albumin-heparin conjugate $(5 \mathrm{mg} / \mathrm{ml}$ in PBS) was first pipetted into the wells of a polystyrene plate. After $1 \mathrm{~h}$ incubation the albumin and albumin-heparin conjugate solutions were discarded and the wells were washed with PBS as described above. Then $60 \mu \mathrm{l}$ of AT III solutions $\left(10^{-5}-2 \times 10^{-1} \mathrm{mg} / \mathrm{ml}\right.$ in PBS $)$ or plasma (undiluted $-10^{5}$ times diluted in PBS) were added to the preadsorbed surfaces and incubated for $1 \mathrm{~h}$. The plasma and AT III solutions were then discarded and the wells were washed with PBS using the procedure described above. Subsequently $50 \mu \mathrm{l}$ of anti-AT III solution was added and the remainder of the test was conducted as described before.

\section{RESULTS}

Table 1 presents the results of the fractionation of albumin-heparin conjugate with immobilized AT III. Since the compositions of the different conjugates do not differ substantially, only the adsorption isotherm of nonfractionated albumin-heparin conjugate on polystyrene was determined and compared with the one obtained for albumin.

Table 1 Characterization of albumin-heparin conjugates

\begin{tabular}{lcc}
\hline Conjugate & Weight \% of heparin & $\begin{array}{c}\text { Antirnagulant activity } \\
\text { in U/mg heparin }\end{array}$ \\
\hline nonfractionated & $10.9 \pm 0.5$ & $76 \pm 6$ \\
high affinity & $10.8 \pm 0.6$ & $150 \pm 12$ \\
low affinity & $9.3 \pm 0.4$ & $13 \pm 4$ \\
\hline
\end{tabular}

${ }^{*}$ Using an APTT assay with heparin $(170 \mathrm{U} / \mathrm{mg})$ as a standard. 
Figure 1 shows the adsorption isotherms observed for albumin and albumin-heparin conjugate on polystyrene as studied with the two step immuno assay. At higher concentrations $\left(>10^{-1} \mathrm{mg} / \mathrm{ml}\right)$, extinctions are statistically indistinguishable for albumin and the albumin-heparin crnjugate, whereas at lower concentrations $\left(10^{-5}-10^{-2} \mathrm{mg} / \mathrm{ml}\right)$ slightly lower extinctions for the albumin-heparin conjugate were usually observed ( 5 independent experiments).

Figure 2 shows the adsorption isotherm of AT III onto a polystyrene surface. When plasma or plasma dilutions (up to $10^{6}$ times) were used as a source of AT III, no adsorption of AT III onto polystyrene could be detected.

Figure 3 shows the results of the adsorption of AT III onto polystyrene preadsorbed with albumin, nonfractionated albumin-heparin conjugate and low and high affinity albumin-heparin conjugate. Besides a significant adsorption of AT III onto nonfractionated and high affinity albumin-heparin conjugate, surprisingly, also on albumin and low affinity albumin-heparin conjugate preadsorbed polystyrene some adsorption of AT III was observed. As an internal control, AT III adsorption from PBS containing a

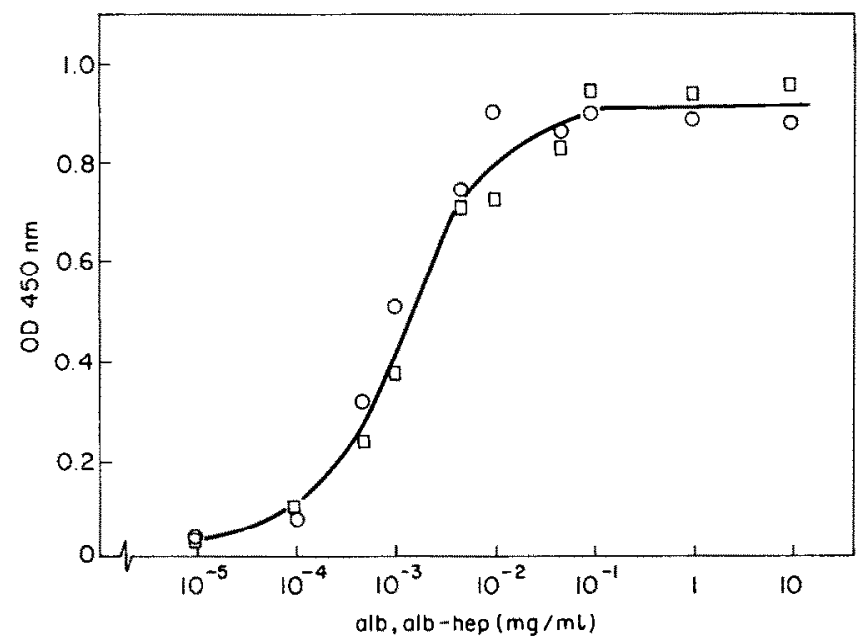

Figure 1 Adsorption isotherms of albumin (O) and albumin-heparin conjugate (D) on polystyrene. All plotted points are the mean of 5 measurements.

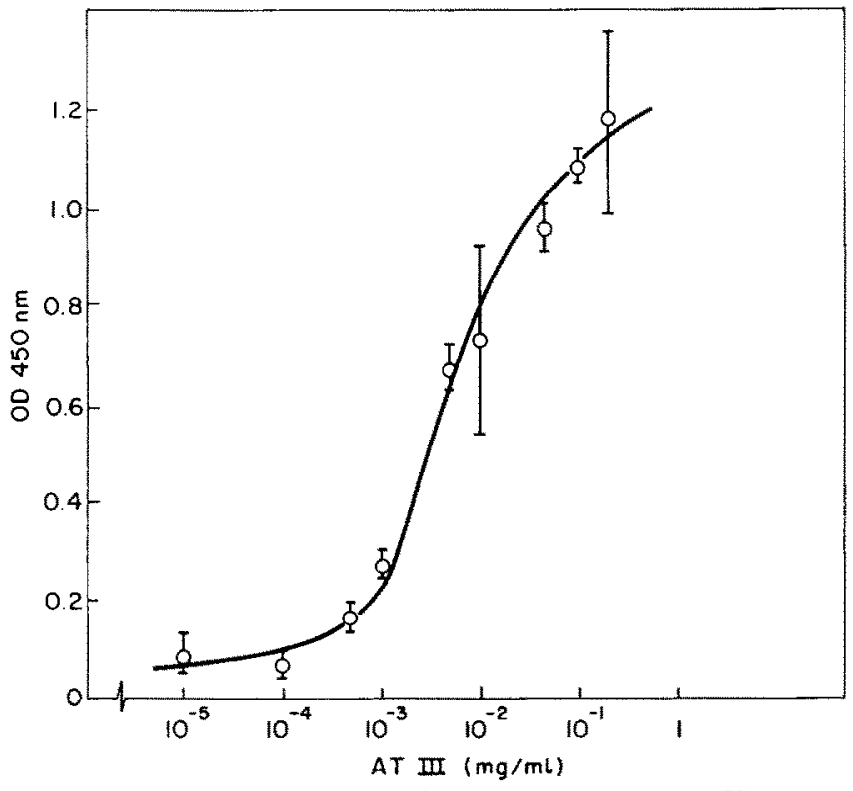

Figure 2 Adsorption isotherm of AT III on polystyrene. All plotted points are the mean $( \pm S . D$.$) of 3-4$ measurements.

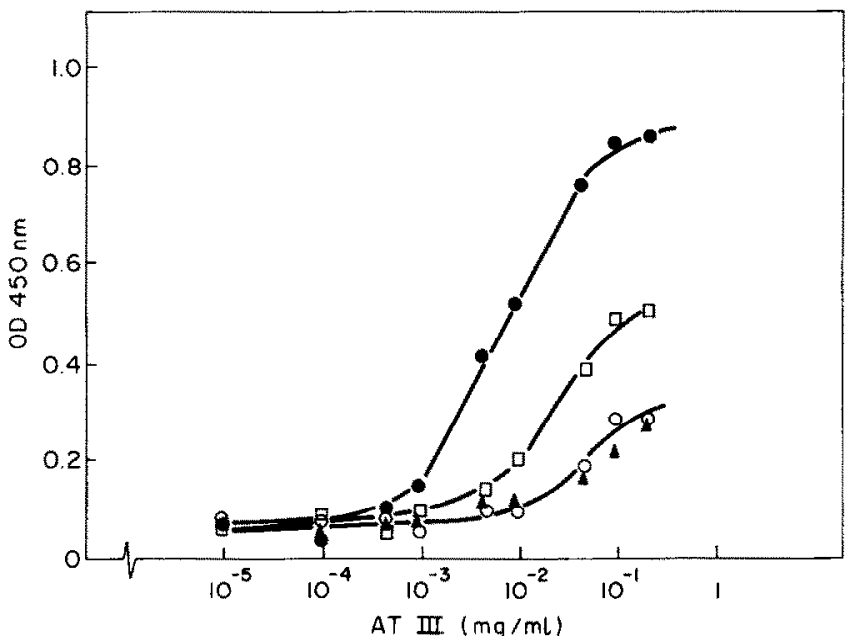

Figure 3 Adsorption of AT III from buffer containing different concentrations of purified AT III onto polystyrene preadsorbed with albumin (0), nonfractionated albumin heparin coniugate (ㅁ), high affinity albumin-heparin conjugate (•) and low affinity albuminheparin conjugate (4). All plotted points are the mean of 3-4 measurements.

physiological concentration of AT III $\left(0.2 \mathrm{mg} / \mathrm{ml}^{22}\right)$ was studied for each polystyrene plate used. The extinctions observed for adsorption of AT III onto preadsorbed albumin and albumin-heparin conjugate surfaces can then be related to the extinctions obtained for AT III adsorption from a $0.2 \mathrm{mg} / \mathrm{ml}$ solution onto bare polystyrene. From Figure 3 it can be calculated that the percentage AT III adsorption of surfaces preadsorbed with albumin, low affinity albumin-heparin conjugate, nonfractionated albumin-heparin conjugate and high affinity albumin-heparin conjugate was $21 \%, 21 \%, 38 \%$ and $65 \%$ respectively. Dependent on the batch of polystyrene plates and AT III used, the AT III adsorption ratios differed widely. For preadsorbed albumin, values between 15 and $70 \%$ were observed and for preadsorbed albumin-heparin conjugate (nonfractionated) these values varied from $35-100 \%$. In spite of the relatively large differences in AT III adsorption percentages observed on the same protein coating, in every experiment the albumin-heparin conjugate preadsorbed surfaces showed a significant higher adsorption of AT III than the albumin preadsorbed surfaces. The adsorption of AT III onto albumin preadsorbed surfaces could not be reduced by increasing the concentration of the albumin solution (up to $10 \mathrm{mg} / \mathrm{ml}$ ). In addition, no reduction in adsorption of AT III onto albumin preadsorbed surfaces was observed when after the incubation of the albumin preadsorbed surfaces with AT III the wells were washed with PBS containing $0.75 \mathrm{M} \mathrm{NaCl}$.

Figure 4 shows the adsorption behaviour of AT III on surfaces preadsorbed with albumin and different albuminheparin conjugates using plasma or plasma dilutions as a source of AT III. From this figure it appears that high affinity and nonfractionated albumin-heparin conjugate preadsorbed surfaces bind substantial amounts of AT III. On the other hand on surfaces preadsorbed with albumin and low affinity albumin-heparin conjugate no AT III adsorption from plasma could be detected with the EIA technique used.

\section{DISCUSSION}

No substantial differences in adsorption behaviour of albumin and albumin-heparin conjugate on polystyrene 


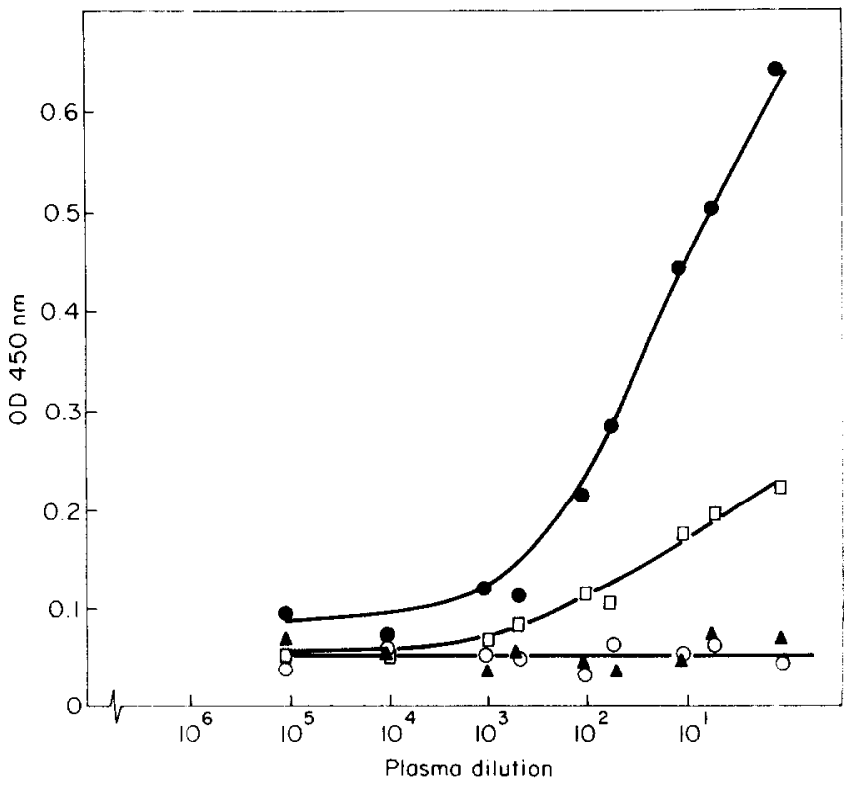

Figure 4 Adsorption of AT III from plasma and plasma dilutions in buffer onto polystyrene preadsorbed with albumin (O), nonfractionated albumin-heparin conjugate ( $\square)$, high affinity albuminheparin conjugate $(\bullet)$ and low affinity albumin-heparin conjugate (A) All plotted points are the mean of 3-4 measurements.

were observed, with the EIA technique used. The observation that at lower concentrations of albumin and albumin-heparin conjugate the extinctions for albuminheparin conjugate were slightly lower than for albumin indicates that either the surface concentration of albumin-heparin conjugate is slightly lower or the immunological affinity of anti-albumin for the albuminheparin conjugate is lower than for albumin. Possibly the binding of heparin to albumin blocked some of the antialbumin binding sites present on the albumin molecule.

As known from affinity chromatography data, immobilized heparin is able to bind AT $11^{21}$ as well as a number of other plasma proteins such as factor $\mid X$ and $X I^{15,23}$. As expected, polystyrene preadsorbed with high affinity and nonfractionated albumin-heparin conjugate binds a significant amount of AT III when exposed to buffer containing AT III or to plasma. In all experiments, higher amounts of AT III were bound to preadsorbed high affinity albumin-heparin conjugate than to nonfractionated conjugate. This can be explained by the observation that only $30-40 \%$ of nonfractionated heparin is able to bind AT $\|\left.\right|^{24,25}$. Surprisingly, albumin and low affinity albumin-heparin preadsorbed surfaces also bind some AT III when exposed to buffer containing purified AT III. Three possible explanations for this observation can be given:

(1) adsorbed albumin binds AT III;

(2) the polystyrene surface was not completely coated with albumin, providing free surface for binding with AT III;

(3) AT III replaces albumin from the polystyrene surface.

The following observations are of importance: AT III bound to albumin preadsorbed polystyrene surfaces could not be removed by washing with $0.75 \mathrm{M} \mathrm{NaCl}$ which indicates that electrostatic interactions play a minor role; when polystyrene was precoated with albumin using solutions with a concentration of $10 \mathrm{mg} / \mathrm{ml}$ instead of $5 \mathrm{mg} / \mathrm{ml}$ no decrease in the adsorption of AT III was observed. Exchange of preadsorbed albumin with proteins in solution has been reported in the literature ${ }^{26,27}$ and because the EIA technique is very sensitive, only a small amount of AT III which has displaced albumin can result in a substantial extinction. No adsorption of AT III from plasma onto albumin preadsorbed surfaces could be detected, which indicates that a possible binding of AT III from buffer solutions to adsorbed alburmin does not have a physiological meaning.

The fact that the heparin moiety of adsorbed albumin-heparin conjugate can bind AT III indicates that the adsorption of albumin-heparin conjugate mainly occurs via the albumin portion with the heparin moiety residing in the aqueous solution phase.

From the study, it can be concluded that after contact between plasma and albumin-heparin conjugate preadsorbed polystyrene, adsorption of AT III takes place. It was demonstrated that this specific adsorption was due to interaction between AT III and the heparin moiety of the conjugate. The binding is dependent on the type of heparin (low or high affinity for AT III) used. From the fact that AT III is specifically adsorbed from plasma onto nonfractionated and high affinity albumin-heparin conjugate preadsorbed surfaces, it can be concluded that for these surfaces AT III also plays a role in the subsequent interaction with clotting factors and platelets.

\section{ACKNOWLEDGEMENTS}

The authors thank the American Red Cross for their gift of purified AT III. This research was supported by Grant HL17623-09 of the National Institutes of Health. One of the authors (W.B.) thanks Organon Technika for financial support.

\section{REFERENCES}

Villanueva, G.B. and Danishefsky, I., Evidence for a heparin induced conformational change of antithrombin III, Biochem. Biophys. Res. Comm. 1977, 74, 803-809

2 Einarsson, R. and Andersson, LO., Binding of heparin to human antithrombin III as studied by measurements of tryptophan fluoresence, Biochim. Biophys. Acta 1977, 490, 104-111

3 Stone, A.L, Beeler, D., Oosta, G. and Rosenberg, R.D., Circular dichroism spectroscopy of heparin-antithrombin interactions, Proc. Natl. Sci. USA 1982, 79, 7190-7194

4 Björk, I. and Lindahl, U., Mechanism of the anticoagulant action of heparin. Molecular and Cellular Biochemistry 1982, 48, 161 182

5 Salzman, E.W., Rosenberg, R.D., Smith, M.H., Lindon, J.N. and Favreau, L. Effect of heparin and heparin fractions on platelet aggregation, J. Clin. Invest. 1980, 65, 64-73

6 Yamamoto, M., Watanabe, K., Ando, Y., Iri, H., Yoshii, Y., Imai, M., Sugiura, K. and Ikeda, Y., On the mechanism of heparin induced platelet aggregation, Thrombos. Res. 1982, 26, 159164

7 Lindon, J. Rosenberg. R., Merrill. E. and Salzman, E., Interaction of human platelets with heparinized agarose gel, J. Lab. Clin. Med. 1978, 91, 47-59

8 Ehrlich, J., Long term thromboresistance of heparinized surfaces, Polymer Engineering and Science 1975, 15. $281-285$

9 Wilson, J.t., Heparinized polymers as thromboresistan biomaterials, Polym. Plast. Technol. Eng. 1981, 16, 119-208

10 Ebert, C.D. and Kim, S.W., Heparin/polymers for the prevention of surface thrombosis, in Medical Applications of Controlled Release Technology, (Ed. Robert Langer). CRC Press, (in Press)

11 Miura. Y., Aoyagi. S., Kusada, Y. and Miyamoto. K.. The characteristics of anticoagulation by covalently immobilized heparin, J. Biomed. Mater. Res. 1980, 14, 619-630 
12 Goosen, M.F.A., Sefton, M.V. and Hatton, M.W.C., Inactivation of thrombin by antithrombin III on a heparinized biomaterial, Thrombos. Res. 1980, 20, 543-554

13 Hennink, W.E., Feijen, J., Ebert, C.D. and Kim, S.W., Covalently bound conjugates of albumin and heparin: synthesis, fractionation and characterization, Thrombos. Res. 1983, 29. $1-13$

14 Hennink W.E Dost L. Feijen, J and Kim S.W Interaction of albumin-heparin conjugate preadsorbed surfaces with blood Trans. Am. Soc. Artif. Intern. Organs 1983, 29, 200-205

15 Hennink, W.E., Dost, L., Kim, S.W., van Aken, W.G. and Feijen, J., Proc. 5th Seminar: Biomaterials in artificial organs, Strathclyde, Scotland, 12-13 September, 1983, (in Press)

16 Hennink, W.E. Kim, S.W. and Feijen, J., (to be published)

17 Breemhaar, W., Ellens, D.J., Beugeling, T. and Bantjes, A., A novel application of a two step immuno assay for the investigation of the blood compatibility of materials, Life support systems, Proc. IX Ann. Mtg. ESAO, (Ed. J. Belangen, W.B Saunders Co Ltd, Eastbourne (UK), 1982, pp 295-300

18 Breemhaar, W. Brinkman E. Ellens, D.J. Beugeling T, and Bantjes, A., Preferential adsorption of high density lipoprotein from blood plasma onto biomaterial surfaces, Biomaterials $1984,5,269-274$.

19 Carlsson, J., Drevin, $H_{\text {, }}$ and Axén, R., Protein thiolation and reversible protein-protein conjugation. $N$-succinimidyl $3-12$ pyridyldithio) propionate; a new heterobifunctional reagent, Rinchem. 1978, 173, 723-737 colorimetric determination of heparin, Canadian $J$. of Phys. Pharm. 1967, 45, 787-794

21 Miller-Andersson, M., Borg, $H$. and Andersson, LO., Purification of antithrombin III by affinity chromatography, Thrombos. Res. $1974,5,439-452$

22 Harpel, P.C., Blood proteolytic enzyme inhibitors: their role in modulation blood coagulation and fibrinolytic enzyme pathways, in Hemostasis and thrombosis, (Eds. R.W. Colman, J. Hirsch, V.J. Marder, and E.W. Salzman), J.B. Lippincott Co. Philadelphia, USA, 1982, chapter 58, pp 738-747

23 Danishefsky, I. and Tzeng, F., Preparation of heparinlinked agarose and its interaction with plasma, Thrombos. Res. $1974,4,237-246$

24 Hook, M., Bjork, I., Hopwood, J. and Lindahl, U., Separation of high- and low-activity heparin species by affinity chromatography on immobilized antithrombin III, FEBS Lett. 1976, 66, 90-93

25 Anderson, LO., Barrowcliffe, T.W., Holmer, E., Johnson, E.A. and Sims, G.E.C., Anticoagulant properties of heparin fractionated by affinity chromatography on matrix-bound antithrombin III and by gel filtration. Thrombos. Res., 1976, 9, 575-583

26 Brash, J.L. Uniyal, S. and Samak, $Q$, Exchange of albumin adsorbed on polymer surfaces, Trans. Am. Soc. Artif. Intern. Organs 1974, 20, 69-76

27 Morrissey, B.W., The adsorption and conformation of plasma proteins: a physical approach, in The behaviour of blood and its components at interfaces. (Fds I. Vroman, and F. Leonard), Ann. N.Y. Acad. Sci. 1977, 283, 50-64 